\title{
ОБЗОРЫ
}

\section{Интеллектуальный капитал: его идентификация и роль в экономике знаний}

\author{
Блинов С.C. ${ }^{25}$
}

Сегодня интеллектуальный капитал является одним из актуальных направлений в финансовом менеджменте. $B$ статье отображена степень значимости данного ресурса как на уровне государства, так и на уровне компаний. Представлены теоретикометодологические аспекть интеллектуального капитала, касающиеся формулировки его определения $и$ критического анализа слабых $и$ сильных сторон моделей оченки интеллектуального капитала. Выделень основные характеристики интеллектуального капитала и его отличительные черты в сравнение с денежно-материальными ресурсами. Сделан вывод о том, что выполнение данных задач в совокупности может способствовать достижению иели по формированию новых рычагов управления стоимостью компании.

$$
\text { JEL: } G 30
$$

Ключевые слова: интеллектуальный капитал, модели оценки, отноченческий капитал, организационный капитал, человеческий капитал, денежно-материальные ресурсы

\section{Новая стадия развития экономики: ключевой фактор роста - знания}

Сегодня наряду с концепцией управления стоимостью фирмы появилась расширенная концепция управления, основанная на максимизации ценности компании для всех стейкхолдеров. Последняя инкорпорирована в различные элементы интеллектуального капитала, которые по своим свойствам и характеристикам отличаются от традиционных материально-денежных ресурсов. Поскольку на сегодняшний день роль интеллектуального капитала растет как на уровне корпоративного управления, так и на уровне государственных структур, то актуально рассмотреть ключевые свойства, особенности моделей оценки интеллектуального капитала и его отличия от традиционных типов ресурсов.

В течение последних десятилетий произошел существенный прорыв в области науки, включающий резкое развитие информационных технологий СМИ и коммуникаций в целом. Данные факторы предопределили переход материально ориентированной экономики в состояние, когда знания, интеллектуальная собственность, нематериальные активы, интеллектуальный капитал играют гораздо большую роль как в жизнедеятельности индивидов, так и в функционировании, развитии компаний и государств в целом. Более того, ориентация экономики на развитие технологий, в первую очередь информационных, связана с рядом отличительных свойств данных ресурсов от традиционных и связанных с ними преимуществ.

\footnotetext{
25 Аспирант, преподаватель кафедры финансового менеджмента НИУ-ВШЭ - Пермь, младший научный сотрудник Лаборатории инвестиционного анализа (Пермь).
} 
Свойства традиционных и информационных ресурсов ${ }^{*}$

\begin{tabular}{|l|l|}
\hline \multicolumn{1}{|c|}{ Традиционные } & \multicolumn{1}{|c|}{ Информационные } \\
\hline Материальные потоки и запасы & Нематериальные потоки и запасы \\
\hline Частное благо & Общественное благо \\
\hline Ограниченные & Неограниченные \\
\hline Тиражируемые с большими затратами & Тиражируемые с малыми затратами \\
\hline $\begin{array}{l}\text { Практически отсутствуют сетевые эффекты } \\
\text { и положительные внешние экстерналии, } \\
\text { значительные издержки на координацию }\end{array}$ & $\begin{array}{l}\text { Наличие сетевых эоложительных внешних экстерналий } \\
\text { полев }\end{array}$ \\
\hline
\end{tabular}

Гапоненко А.Л. Управление знаниями. Как превратить знания в капитал. М.: Эксмо, 2008. $400 \mathrm{c}$.

Информационные ресурсы представляют собой чаще как общественное благо, потребление которого одним потребителем не исключает его потребления другими. Иными словами, знания и информация неотчуждаемы. По мере увеличения степени использования знаний в современном производстве в него включается все большее количество общественных благ. Вместе с тем, если не вводить искусственные ограничения на отношения собственности, то почти все знания, которые можно кодифицировать или уже прошедшие этот процессе, являются общественным благом. Однако в экономике, основанной на знаниях, нельзя забывать про такой элемент, как авторское и патентное право, которое позволяет многим компаниям иметь устойчивые конкурентные преимущества. Данный инструмент переводит интеллектуальный продукт из состояния общественного блага в частное, заставляя потребителей оплачивать затраты на генерацию и распространение этого продукта, тем самым увеличивая выгоды компаний, владеющих тем или иным патентом и т.д.

Наряду с вышесказанным, информационные ресурсы, воспроизводимые людьми, не ограничены. Ярким примером может служить наличие сети Интернет. Боле того, традиционные ресурсы тиражируются с большими затратами: «например, чтобы сделать автомобиль, необходимо затратить почти столько же труда и капитала, сколько было затрачено на производство предыдущего, в то время как при тиражировании информационного ресурса стоимость процесса копирования информации, как правило, мала» [Гапоненко, 2008]. Кроме того, использование информационных ресурсов характеризуется эффектом сетевого взаимодействия и положительными внешними эффектами. В обычных условиях ценность аппарата или устройства определяется его индивидуальными свойствами и практически не зависит от степени распространенности, в то время как в Сети - чем больше входящих в нее элементов, тем больше полезность для индивида и соответствующий экономический эффект. Примером может служить развертывание телефонной и мобильной сети, Интернета, факсимильной почты, использование единого стандарта программного обеспечения и т.д. Здесь внешний эффект проявляется в связях между потребителями. Аналогию этого явления можно отобразить следующим образом: «каждый индивид заинтересован, чтобы документ, созданный и обработанный в рамках одного программного обеспечения, мог быть прочитан и обработан другим пользователем; каждый потребитель заинтересован в том, чтобы сотовый телефон работал одинаково устойчиво и в конкретном городе, и в любой точке страны или мира» [Гапоненко, 2008].

Наиболее наглядным подтверждением вышесказанному является тот факт, что число компаний, вошедших в S\&P500 и зарегистрированных в NASDAQ, постоянно растет. B начале 1990-х годов в листинг NASDAQ входило только порядка 25 компаний, что составляло менее 5\% общей капитализации компаний, представленных в S\&P500. К 1999 году, на пике развития доткомов компаний, в котировальный лист NASDAQ уже входило 47 компаний, чья капитализация в рамках S\&P500 составляло уже 20,6\%. Даже после кризиса 
доткомов компаний, на конец 2003 года, в индекс S\&P500 были включены 74 компании, чей удельный вес в индексе составлял 16,7\% его величины [Руус, 2008]. Другим примером являются данные мирового индекса Morgan Stanley, который показал, что стоимость таких компаний превышает в 2-9 раз балансовую стоимость активов данных фирм соответственно [Chun-Yao Tseng, 2005]. Кроме того, различные исследования отражают, что интеллектуальный капитал составляет 60-75\% от корпоративной стоимости компаний [Van den Berg, 2005]. Сегодня данные компании являются одними из наиболее эффективных предприятий с позиции генерирования добавленной стоимости. К их числу относятся Microsoft, Google, eBay, Amazon и т.д. Данные компании, по сути, являются символом успешности американской экономики, которая одной из первых осознала всю важность знаний в рамках рыночной системы и направила значительные ресурсы как в интеллектуальном, так и финансово-законодательном плане на развитие экономики, основанной на знаниях.

К сожалению, Россия по-прежнему выступает в роли догоняющего в данном процессе, что отчасти связано с политическим и экономическим кризисом 1990-х годов, когда экономика только ступила на путь рыночных реформ. К слову, на рубеже XX-XXI веков доля наукоемких технологий в промышленной продукции России составляла менее $1 \%$ от мирового хозяйственного оборота. Присутствие российских инновационных продуктов на мировых рынках измеряется величиной $0,2-0,3 \%$, тогда как на долю США приходится примерно 40\% [Ракитов, 2004]. Более того, если в Западной Европе новые достижения используют $80 \%$ компаний, то в России - всего $5 \%$. Мировой рынок российских технологий приближается к 1,5 трлн долл., тогда как российский - к 8 млрд (порядка 0,5\%). Отчасти это связано с тем, что российская экономика не в состоянии использовать открытия отечественных ученых. Так, мы находимся на шестом месте по генерированию идей, патентов и других объектов интеллектуальной собственности, но по способности капитализировать данные объекты мы лишь на 90-м [Гапоненко, 2008].

Состояние наукоемкого сектора в любой стране наиболее ясно отражает доля расходов на научные исследования и разработки в ВВП страны. В среднем они должны составлять от 2 до 4\%. Так, в США, Японии и Германии эти расходы приближаются к 3\%, во Франции и Великобритании держатся на уровне $2-2,5 \%$, в Китае поднялись до 4\%, а в Индии составляют порядка $10 \%$. В России в период после развала СССР и к настоящему моменту в среднем расходы на научные исследования и разработки составляют лишь $1,17 \%$ от ВВП [Гапоненко, 2008]. Модернизация экономики на базе отечественных технологий требует значительного роста инвестиций в науку. Разумеется, можно сказать, что осознание важности данного элемента уже пришло, подтверждение этому можно найти в осуществлении проекта создания отечественной силиконовой долины в Сколково. Однако уже сейчас в течение 5 лет необходимо вкладывать в развитие технологий не менее $5 \%$ ВВП для того, чтобы приблизиться к уровню развития технологий нынешних лидеров [Гапоненко, 2008]. Однако наряду с недавним кризисом в мировой экономике данный сценарий для России выглядит весьма оптимистично. Тем не менее сам факт осознания важности технологической сферы и проекты по созданию национальных научных центров уже являются существенным этапом для дальнейшего развития экономики в инновационном направлении.

Таким образом, осознавая высокую степень значимости неосязаемых активов в экономике знаний для государства и корпоративного сектора, становится необходимым определить теоретико-методологические результаты, достигнутые в данном направлении.

\section{Теоретико-методологические аспекты интеллектуального капитала}

Первым данное понятие интеллектуального капитала предложил экономист Джон Кеннет Гэлбрейт, который написал своему коллеге экономисту Майклу Колецки следующее: «Интересно, понимаешь ли ты, сколь многим обязан окружающий мир тому 
интеллектуальному капиталу, который ты дал за последние десятилетия» [Bontis, 2001]. Среди первопроходцев, кто исследовал природу интеллектуального капитала, следует особо выделить лауреата многих премий и члена редколлегии журнала Fortune Т. Стюарта. В статье «Сила интеллекта: как интеллектуальный капитал становится наиболее ценным активом Америки» он представил интеллектуальный капитал как сумму всего того, что знают работники компании и что дает конкурентное преимущество компании на рынке, тем самым способствуя увеличению благосостояния фирмы: «...патенты, процессы, управленческие навыки, технологии, опыт и информация о потребителях и поставщиках. Объединенные вместе, эти знания составляют интеллектуальный капитал» [Stewart, 1991]. Другая распространенная точка зрения на интеллектуальный капитал сформулирована главой консалтинговой компании The Technology Broker Энни Брукинг: «мы идентифицировали четыре категории неосязаемых активов: человеческие ресурсы, права на интеллектуальную собственность, инфраструктуру и положение на рынке - которые обозначаются общим термином интеллектуальный капитал» [Брукинг, 2001]. Известный шведский экономист Лэйф Эдвинссон определяет интеллектуальный капитал как знание, которое можно конвертировать в стоимость. Эдвинссону вторит Даум, который рассматривает интеллектуальный капитал в виде «основанных на связях структурированных знаниях и способностях, обладающих потенциалом развития и создания стоимости» [Daum, 2002]. В то же время Руус говорит об интеллектуальном капитале, как «о всех неденежных и нематериальных ресурсах, полностью или частично контролируемых организацией и участвующих в создании ценности» [Руус, 2008].

Несмотря на явное присутствие в определениях такого компонента, как знания, многие формулировки интеллектуального капитала возникли исходя из различных аспектов проблем идентификации интеллектуальных ресурсов, их применения для создания ценности, а также оценки и измерения данного типа капитала. В продолжение данной темы: если рассмотреть вопросы создания методологической основы оценки интеллектуального капитала, то многие специалисты говорят, что оценка данного компонента не является наукой, по крайней мере на данной стадии своего развития. Это обусловлено тем, что не существует универсальной и общепринятой методологии оценки и единой концепции инкорпорирования интеллектуального капитала в систему управления фирмой. В итоге многие исследователи посвящают себя тому, что пытаются решить данную методологическую проблему. Примером тому могут служить результаты исследований следующих авторов:

- Артур Андерсон [Andersen, 1992] разбил методы оценки на следующие категории: стоимость затрат, рыночная и экономическая стоимость.

- Вильямс [Williams, 2001] разделил модели в четыре подхода: методы прямого расчета интеллектуального капитала, рыночной капитализации, доходности активов и системы сбалансированных показателей.

- Бонтис [Bontis, 2001] и Лейларт [Leliaert, 2003] обнаружили, что многие модели используют аналогичные теории и показатели, но при этом пользуются разными обозначениями.

- Mapp [Marr, 2003] анализировал различные методологии оценки и обнаружил эмпирические доказательства их эффективности.

- Пайк и Pyyc [Pike and Roos, 2004] оценили строгость методологий оценки интеллектуального капитала, сравнивая с теорией оценки, и пришли к тому, что необходима пятая категория идентификации моделей: система оценки интеллектуального капитала для каждой компании.

Таким образом, мы можем выделить, что с позиции теоретико-методологических основ понятие интеллектуального капитала не является общепринятым, а методология не унифицирована, что объясняется различиями в целеполагании, которое исследователи определяют для себя в индивидуальном порядке. Подобное обстоятельство порождает множество моделей оценки интеллектуального капитала, наиболее известные из которых отображены в Приложении 1. 
Соответственно для топ-менеджмента компании интерес представляет не столько описание данных моделей и методология их расчета, сколько их преимущества и недостатки при внедрении и дальнейшем использовании в рамках системы управления. Одним из главных достоинств как Монитора Неосязаемых Активов, так и Навигатора Скандия является то, что они позволяют выявлять сильные и слабые стороны компании в сфере ее неосязаемых активов, выступая в роли инструмента внутреннего мониторинга состояния компании. Однако оценка данными методами требует значительных усилий для формирования необходимой информационной базы, результат использования которой представляют собой комбинацию количественных и описательных показателей. Последние связаны с субъективностью, что делает сложным их применение по организациям [Liebowitz \& Wright, 1999]. Кроме того, в данных моделях нет места финансовой, расчетной стоимости неосязаемых активов. В свою очередь, нельзя однозначно сказать, что активы, которые рассматриваются данными моделями в роли элементов интеллектуального капитала, являются наиболее важными для компаний. Следующая проблема заключается в связи с классическим подходом построения бухгалтерского баланса, т.е. ценность различных категорий в рамках моделей зависит от представленной в отчетности на данный момент времени информации, которая при этом не включает данных относительно прогнозируемых денежных потоков и не отвечает на вопрос: что управляет стоимостью данных категорий неосязаемых активов? [Liebowitz \& Wright, 1999]

Подобная проблема количественной оценки и отсутствия возможности проводить сравнительный анализ по компаниям существует и в Сбалансированной Системе Показателей [Andriessen, 2004; Roos, 1997], говоря о которой, Бонтис [Bontis, 1998], в частности, делает акцент на жесткости системы взаимосвязанных показателей как таковой. Имеется в виду, что в данную модель не инкорпорированы такие факторы, как конкуренция и технический прогресс, вопросы окружающей среды, общественные и социальные аспекты [Marr \& Adams, 2004], что делает параметры внешней среды статичными, хотя на самом деле они изменяются [Bourne, 2002]. Кроме того, было выявлено, что такой элемент внутренней среды компании, как организационная культура, в рамках модели остается неизменным, что может создать прецедент управления менеджментом неактуальными на данный момент показателями [Arnulf, 2005]. Вместе с тем Канджи [Kanji, 2002] установил, что данная модель является концептуальной по сути и ей недостает возможностей к построению системы измерения, поскольку показатели модели нечетко определены, что усложняет процесс выявления и измерения взаимосвязи между ними. Наряду с этим Система Сбалансированных Показателей смешивает воедино общепринятые финансовые показатели, которые могут быть применены к большинству подразделений в рамках организации [Slovic \& MacPhilliamy, 1974] со специфическими показателями, относящимися к конкретному организационному подразделению, для удовлетворения потребностей которого они были разработаны [Roberts, Albright\&Hibbets, 2004]. Несмотря на вышеупомянутое, говоря о Сбалансированной Системе Показателей, мы можем выделить, что наряду со способностью коррелировать показатели со стратегическим целями [Marr, 2004] она позволяет измерять улучшения в сферах деятельности компании. Подобное обстоятельство говорит о том, что данная модель была разработана именно как управленческая основа для мониторинга состояния и реализации стратегических намерений фирмы, а не как установленная система измерений.

О наличии последней мы можем говорить, если рассмотрим модель Технологического Брокера Брукинг, одним из основных преимуществ модели которой является то, что по сути она представляет собой развитие данного направления через разработку определенных индикаторов, с помощью которых компания может оценить свой интеллектуальный капитал. Однако данная модель находится на ранней стадии разработки, поскольку в ней попрежнему отсутствует последовательная количественная оценка стоимости неосязаемых активов. Это обусловлено тем, что Технологический Брокер требует проведения анализа для трансформации качественных результатов в количественные. Данная трансформация 
является слабым местом модели, так как разные люди могут по-разному переходить от качественных значений к количественным, тем самым усугубляя проблему субъективности оценки. В дополнение к этому Технологические Брокер не может помочь аудиторским службам в решении самых сложных в данной сфере вопросов: как идентифицировать релевантные к области аудита неосязаемые активы, как определить, что является областью аудита в данной сфере, и как поставить цель для нее [Andriessen, 2004].

Говоря о других моделях оценки интеллектуального капитала, автор модели Технологический Брокер Энни Брукинг особо выделяла соотношение Рыночной и Балансовой Стоимости и Q Тобина. Основное преимущество данных моделей она видела в отражении ими того, насколько хорошо фирма управляет своими неосязаемыми активами [Brooking, 1997]. Кроме того, входные данные в рассматриваемых моделях являются легкодоступными, а полученные результаты - понятными для инвесторов. В то же время Гу и Лев [Gu and Lev, 2001] в своих исследованиях говорят, что результаты данных моделей являются просто числами, которые слишком изменчивы и подвержены колебаниям. Другие исследователи также выделяют две основные проблемы: во-первых, использование балансовой стоимости, основанной на исторических затратах; во-вторых, применение рыночной стоимости, которая подвержена влиянию множества факторов, находящихся вне сферы контроля компании [Bouteiller, 2002; Stewart, 1997]. Первую проблему решает Q Тобина, в рамках которого нейтрализован эффект использования различных амортизационных политик [Bouteiller, 2002; Stewart, 1997]. Вторая проблема является ключевой и остается не до конца изученной, поскольку нельзя однозначно сказать, что прирост рыночной стоимости бизнеса связан только с неосязаемыми активами [Andriessen, 2004].

К числу моделей, в которых присутствует строго определенная система измерений, также можно отнести модель EVA, которая в общем связывает принципы финансового планирования, экономического анализа намечаемых капиталовложений, целеполагания, систем показателей и стратегического планирования для получения одного-единственного индикатора, который, как верят его разработчики, является наиболее простым для понимания нефинансовыми менеджерами. Подобное обстоятельство является одним из преимуществ данной модели, к числу которых можно также отнести учет альтернативных затрат, т.е. наличие платы за пользование капиталом. Тем не менее затраты на капитал не являются величиной постоянной в большинстве случаев, что делает показатель Экономической Добавленной Стоимости изменяющимся от периода к периоду. Подобное обстоятельство усложняет механизм расчета. Кроме того, модель требует сделать выбор между точностью и сложностью [Bontis et al., 1999]. Модель Добавленной Экономической Стоимости позволяет менеджерам делать корректировки для ее входящих переменных. Однако по мере того как число корректировок растет, сложность модели также увеличивается. Исходя из этого, если итоговый показатель является более точным, то зачастую он достаточно сложен для понимания менеджеров. Другим ограничением модели является использование балансовой стоимости капитала. Балансовые оценки отражают исторические затраты, а не текущие рыночные стоимости и отраслевые характеристики, что отдаляют данную модель от истинного понимания ценности фирмы и ее неосязаемых активов.

Наряду с этим модель Рассчитанной Стоимости Неосязаемых Активов использует отраслевые показатели в механизме расчета, что является одним из ее преимуществ, но не единственным. К числу последних также можно отнести использование публичной относительно доступной информации и наличие инструментария сравнительного анализа по компаниям отрасли [Stewart, 1997]. В целом данная модель является попыткой установить ковариацию между стоимостью неосязаемых активов фирмы и ее уникальной способностью производить и получать знания. Однако в рамках методики необходимо наличие группы компаний-аналогов для оценки избыточных доходов фирмы. Подобное обстоятельство наталкивает нас на проблему потенциального отсутствия группы аналогов, что в свою очередь зависит от специфики отрасли. Кроме того, данная модель не рассматривает 
политику амортизационных отчислений и налогообложения компании индивидуально, что может негативно сказаться на точности определения доходов и, как следствие, на результирующем показателе всей модели [Bouteiller, 2002]. Вместе с тем еще одним упрощением модели является предположение о том, что избыточные доходы и их рост связаны исключительно со стоимостью неосязаемых активов, тем самым нивелируя участие других факторов в создании данных доходов. Например, данная модель игнорирует материальные активы, которые совместно с неосязаемыми активами также участвуют в создании избыточных доходов [Bouteiller, 2002].

Подобная проблема отчасти решена в модели Дохода Капитала Знаний Лева, которая использует доходности материальных и финансовых активов как основу для расчета стоимости неосязаемых активов. Однако данная методология, агрегируя материальные, финансовые и неосязаемые активы, не содержит стоимость синергии, созданной между данными тремя источниками [Andriessen, 2004]. Кроме того, несмотря на то что данная модель широко распространена среди специалистов в области управления знаниями, некоторые исследователи верят в ее ограниченность. Страссманн [Strassmann, 2001] убежден в низкой валидности результирующего показателя модели, поскольку при расчете используются аналитические прогнозы, которые зачастую бывают некорректны и усугубляют проблему субъективности оценки.

Наряду с этим проблему учета синергии можно наблюдать в рамках модели Коэффициента Добавленной Стоимости Интеллектуального Капитала [Andriessen, 2004]. Кроме того, Стюарт [Stewart, 2003] не согласен с предпосылкой о том, что затраты на труд всегда следует относить к инвестициям в персонал. Примером тому служит поправка на рост прожиточного минимума, тарифный разряд или территориальное расположение. В то же время оба автора верят, что у данной модели есть ряд преимуществ. Во-первых, это использование публичной общедоступной информации, которая может быть применена при сравнении компаний между собой [Stewart, 2003]. Кроме того, международные корпорации могут использовать данный подход, чтобы сравнивать интеллектуальные способности их филиалов в целях мониторинга того, насколько хорошо местный менеджмент задействует ресурсы компании. Во-вторых, данную методологию легко понять [Andriessen, 2001].

Исходя из вышесказанного, мы можем свести характеристики рассмотренных моделей в единую структуру, отображенную в Приложении 2.

Таким образом, выделение достоинства и недостатков моделей оценки интеллектуального капитала может дать топ-мененджменту один из критериев при выборе соответствующей модели для ее дальнейшего инкорпорирования в систему управления стоимостью фирмы, декомпозированной до уровня конкретных показателей. В рамках экономики знаний данные меры необходимы для выявления новых рычагов управления стоимостью фирмы, которые будут способствовать улучшению результатов ее деятельности. Однако для этого становится необходимым понимание не только моделей, но и ключевых характеристик интеллектуального капитала.

\section{Ключевые характеристики интеллектуального капитала компании и его структурных компонентов}

Многие исследования определяют следующие отличительные черты интеллектуального капитала:

1. Неосязаемый: «ресурсы формируют основу потенциального конкурентного преимущества, но лишь немногие попадают в официальные документы в поддающиеся проверке формы» [Руус, 2008]. «Действительно, в частности, знания и творческие способности людей нельзя потрогать, имидж компании невозможно пощупать, а моральные ценности нельзя увидеть» [Гапоненко, 2008].

2. Эффект значительных временных задержек: чтобы получить эффект от больших инвестиций в человеческий и инновационный капитал, необходимо время, т.е. 
существует существенный временной лаг, который откладывает общее и немедленное получение выгод от таких инвестиций. Из различных эмпирических исследований известно, что средняя продолжительность ожидания эффектов от исследований и разработок составляет приблизительно 5-9 лет [Bontis, 2001].

3. Эффект с ненулевой суммой: в отличие от традиционных активов, представленных в отчетах, потоки, связанные с интеллектуальным капиталом, не обязательно прибавляются к нулю. Например, огромные финансовые инвестиции в разработку новых информационных систем могут быть потрачены впустую, если информационные системы не подходят для компании или если ее культура не одобряет их использование [Chun-Yao Tseng, 2005].

4. Закон возрастающей предельной отдачи: в то время как земля, капитал и труд следуют закону убывающей отдачи, знания и информация имеют возрастающую отдачу, т.е. созданная с помощью данных компонентов стоимость растет по мере увеличения применяемого и генерируемого интеллектуального капитала. Данное положение отчасти связано с сетевым эффектом взаимодействия, который порождает явление возрастающей предельной полезности и предельной производительности, т.е. чем больше масштаб деятельности в данных условиях, тем больше эффективность использования дополнительно вовлекаемых ресурсов [Гапоненко, 2008].

Для более четкого понимания характеристик интеллектуального капитала необходимо определить основные его элементы и соотнести их с более развернутой интерпретацией вышеописанных параметров. Существует множество подходов к определению структуры интеллектуального капитала, наиболее известные отображены в следующей таблице.

Таблица 2

Подходы к классификации интеллектуального капитала*

\begin{tabular}{|l|lc|}
\hline Aвтор & Классификация \\
\hline Edvinsson, Malone, 1997 & Человеческий и структурный капитал \\
\hline Bontis, 1998 & $\begin{array}{l}\text { Человеческий, структурный и клиентский } \\
\text { капитал }\end{array}$ \\
\hline Stewart, 1997 & $\begin{array}{l}\text { Человеческий, структурный и клиентский } \\
\text { капитал }\end{array}$ \\
\hline Saint-Onge,1996 & $\begin{array}{l}\text { Человеческий, и структурный } \\
\text { отношенческий капитал }\end{array}$ \\
\hline Sveiby,1997 & $\begin{array}{l}\text { Компетенция персонала, внутренняя и } \\
\text { внешняя структура }\end{array}$ \\
\hline Van Buuren, 1999 & $\begin{array}{l}\text { Человеческий, инновационный, процессный } \\
\text { и клиентский капитал }\end{array}$ \\
\hline Roos, 1998 & $\begin{array}{l}\text { Человеческий, } \\
\text { отношенческий капитал }\end{array}$ \\
\hline O`Donnell, O`Regan, 2000 & $\begin{array}{l}\text { Человеческий капитал, внутренняя и } \\
\text { внешняя структура }\end{array}$ \\
\hline
\end{tabular}

*Составлено по: Гаранина Т.В. Структура интеллектуального капитала: вопросы оценки и эмпирического анализа // Вестник Санкт-Петербургского университета. Серия 8. Выпуск 1. 2008. C. $96-117$.

По сути, оперируя различными понятиями, авторы говорят об одних и тех же составляющих, только в своей интерпретации. Мы будем пользоваться трактовкой структуры интеллектуального капитала, предложенной Йораном Руусом, для сравнения по определенным критериям характеристик компонентов интеллектуального капитала с денежными и материальными ресурсами:

1. Степень аддитивности:

а) денежно-материальные ресурсы являются аддитивными, т.е. при их использовании 
их становится все меньше, а при инвестировании - все больше;

б) отношенческие, организационные и человеческие ресурсы не аддитивны по своей природе - их количество не уменьшается просто от того, что их используют, и их не обязательно становится больше просто от того, что в них инвестируют.

2. Форма отдачи на инвестиции:

а) денежно-материальные ресурсы действуют преимущественно согласно закону убывающей отдачи;

б) отношенческие и организационные ресурсы существуют по законам сетевой экономики, т.е. первоначально требуются значительные инвестиции, которые дают очень малую отдачу, прежде чем доход достигнет приемлемого уровня. Через какое-то время после увеличения вложений предельная отдача от инвестиций в эти ресурсы будет увеличиваться, пока не достигнет точки перегиба, после чего дальнейшие предельные инвестиции будут приносить убывающую предельную отдачу;

в) человеческие ресурсы существуют по закону возрастающей предельной отдачи. «Во время интеракций индивиды, обладающие большим, но разными объемами знаний, будут узнавать новое, но дистанция между их объемами знаний будет увеличиваться» [Руус, 2008].

3. Отношение к собственности организации и контроль:

a) денежно-материальные ресурсы находятся в собственности и под контролем организации;

б) отношенческие ресурсы не находятся ни в собственности, ни под контролем организации. В лучшем случае она может влиять на них. Отношения с точки зрения каждой из сторон находятся под контролем другой стороны. «Никакой контракт в мире не поможет помешать стороне, продолжая формально выполнять соглашение, устраниться от сделки мысленно, тем самым не давая ей увенчаться успехом» [Руус, 2008];

в) организационные ресурсы принадлежат организации и контролируются ею. В принципе, они являются единственными из ресурсов интеллектуального капитала, которые находятся в собственности фирмы и контролируются ею. «Эти ресурсы можно продать, хотя и на неэффективных рынках» [Руус, 2008];

г) человеческие ресурсы не принадлежат никому, но при этом контролируются человеком. «То, что человек просто приходит на работу, не означает, что кто-то имеет доступ к его знаниям и умениям. Между компетенцией человека и организацией, которая хочет воспользоваться этим ресурсом, стоит сам человек» [Руус, 2008].

4. Конкурентность во времени:

а) денежно-материальные ресурсы представляют собой конкурентные ресурсы, т.е. они не могут одновременно использоваться для разных целей;

б) отношенческие, организационные и человеческие ресурсы не являются конкурентными, поскольку их можно использовать одновременно для решения нескольких разнородных задач.

5. Исключаемость:

a) денежно-материальные ресурсы обладают полной исключаемостью, т.е. можно юридически защититься от того, чтобы этими ресурсами пользовались другие;

б) отношенческие, организационные и человеческие ресурсы обладают лишь частичной исключаемостью, т.е. очень трудно юридически защититься то того, чтобы другие завладели ими и получали от них экономические выгоды. «Отношения могут быть узурпированы, бренд скопирован, а на основе информации из оригинального патента можно создать его копию. Кроме того, все ресурсы интеллектуального капитала представляют возможности для возникновения проблемы безбилетника» [Руус, 2008];

в) степень информационной асимметрии - в отличие от денежно-материальных ресурсов, отношенческие, организационные и человеческие ресурсы имеют более высокие уровни информационной асимметрии: «в отношении объема и качества этих ресурсов существует неопределенность у покупателя... не существует действительно эффективных рынков для торговли этими ресурсами» [Руус, 2008]. 
Помимо отличий интеллектуальный капитал имеет много общих черт с физическим капиталом (денежно-материальными ресурсами). Оба типа возникают в результате вложения инвестиций, могут приносить своему обладателю доход и в то же время требуют затрат на свое поддержание. Кроме того, оба вида капитала подвергаются моральному износу. Однако нельзя забывать, что степень морального износа (скорость устаревания) гораздо выше у интеллектуальных ресурсов, чем у денежно-материальных. Вместе с тем к особенностям интеллектуального капитала можно отнести то, что он не поддается учету с помощью традиционных методов бухгалтерского учета, который основан на принципе аддитивности всех величин. Более того, структурные элементы интеллектуального капитала взаимодействуют друг с другом в основном нелинейно, усиливая или ослабляя действие друг друга. Отчасти это связано с тем, что интеллектуальный капитал не аддитивен и формируется не суммой его составляющих, а на основе взаимодействия, за счет синергетического эффекта. В ходе взаимодействия различных компонентов интеллектуального капитала можно получить значительный положительный эффект, который будет непропорционален приложенным усилиям. Поэтому одним из факторов успешного генерирования интеллектуального капитала фирмы является эффективное взаимодействие, взаимопроникновение друг в друга структурных компонентов данного вида капитала, что в свою очередь будет способствовать увеличению стоимости компании.

Таким образом, мы можем сказать, что на данном этапе развития экономики ключевым фактором роста являются знания и интеллектуальный капитал в целом. Поскольку данные активы по ряду признаков отличаются от традиционных, подобное обстоятельство делает необходимым для корпоративного сектора и государства поиск новых рычагов управления. Для достижения данной цели первоочередной задачей является понимание того, что из себя представляет интеллектуальный капитал. Следующим можно выделить анализ моделей оценки с точки зрения выявления преимуществ и недостатков, что позволит установить соответствие между критериями выбора модели и целевыми ориентирами компании. Последним является анализ ключевых характеристик интеллектуального капитала, который дает топ-менеджменту возможность создать новые управленческие механизмы на основе выбранных моделей, что тем самым способствует реализации концепции управления стоимостью фирмы, основанной на максимизации ценности для всех стейкхолдеров.

\section{Список литературы}

1. Брукинг Э. Интеллектуальный капитал: ключ к успеху в новом тысячелетии. Питер. 2001. $288 \mathrm{c}$.

2. Гапоненко А.Л. Управление знаниями. Как превратить знания в капитал. М.: Эксмо. 2008. $400 \mathrm{c}$.

3. Гаранина Т.В. Структура интеллектуального капитала: вопросы оценки и эмпирического анализа // Вестник Санкт-Петербургского университета. 2008.Серия 8. Выпуск 1. С. 96-117.

4. Ракитов А.И. Роль высшей школы в создании системы национальной инновационной экономики // Науковедческие исследования. М.: РАН. 2004. С.19.

5. Руус Й., Пайк С., Фернстрём Л. Интеллектуальный капитал: практика управления. СПб: Высшая школа менеджмента. 2008. 436 с.

6. Andriessen, D., Tissen, R. (2001), Weightless Weight - Find your Real Value in a Future of Intangible Assets. London: Pearson Education.. P. 256.

7. Arnulf, J. (2005), What's measured is not necessarily managed: Cognitive contingencies of organizational measurement, Scandinavian Journal of Psychology, 46 (2005) 59-68.

8. Arthur Andersen \& Co. (1992), The Valuation of Intangible Assets. Special Report No. P254. London: Arthur Andersen \& Co.

9. Andriessen, D. (2004), IC Valuation and Measurement: Classifying the State of the Art, Journal of Intellectual Capital, 5(2) (2004) 230. 
10. Bontis, N. (1998), Intellectual capital: An exploratory study that develops measures and models., Management decision, 36(2) (1998) 63-76.

11. Bontis, N., Dragonetti, N.C., Jacobsen, K., Roos, G. (1999), The Knowledge Toolbox: A Review Of The Tools Available To Measure And Manage Intangible Resources, European Management Journal, 17(4) (1999) 391-401.

12. Bontis, N. (2001), Assessing knowledge assets: a review of the models used to measure intellectual capital, International Journal of Management Reviews, 3(1) (2001) 41-60.

13. Bourne, M. (2002), The emperor's new scorecard, Financial World, August (2002) 4850.

14. Bouteiller, Ch. (2002), The Evaluation of Intangibles: Advocating for an Option Based Approach. VIth Alternative Perspectives on Finance Conference, Hamburg, August (2002).

15. Brooking, A. (1997), The management of intellectual capital, Long Range Planning, 3(3) (1997) 365-366.

16. Chun-Yao Tseng, Yeong Jia James Goo. (2005), Intellectual capital and corporate value in an emerging economy: empirical study of Taiwanese manufacturers, R\&D management, 35(2) (2005) 187-202.

17. Daum, J.H. (2002), Intangible Assets, Bonn: Galileo Press GmbH, (2002) 152-154.

18. Gu Feng and Baruch Lev. (2001), Intangible Assets: Measurement, Drivers, Usefulness, Boston University and New York University. URL: http://pages.stern.nyu.edu/ blev/intangibleassets.doc (дата обращения: 27.08.2010).

19. Kanji, G. (2002), Performance measurement system, Total Quality Management, 13(5) (2002) 715-728.

20. Leliaert, P., Candries, W., Tilmans, R. (2003), Identifying and Managing IC: A New Classification, Journal of Intellectual Capital, 4(2) (2003) 202-214.

21. Liebowitz, J. \& Wright, K. (1999), Does measuring knowledge make «cents»?, Expert Systems with Applications, 17 (1999) 99-103.

22. Marr, B., Gupta, O., Pike, S., Roos, G. (2003), Intellectual capital and knowledge management effectiveness, Management Decision, 41(8) (2003) 771.

23. Marr, B. \& Adams, C. (2004), The balanced scorecard and intangible assets: Similar ideas, unaligned, Measuring Business Excellence, 8 (3) (2004) 18-27.

24. Pike, S. and Roos, G. (2004), Measurement Issues in Intellectual Capital - A Review. International Forum of Intellectual Capital. Taiwan, 2004.

25. Roberts, M., Albright, T. \& Hibbets, A. (2004), Debiasing balanced scorecard valuations, Behavioral Research in Accounting, 16 (2004) 75-88.

26. Roos, G. (1997), Measuring your company's intellectual performance, Long Range Planning, 30(3) (1997) 413-426.

27. Slovic, P. \& MacPhilliamy, D. (1974), Dimension commensurability and cue utilization in comparative judgment, Organizational Behavior and Human Performance, 11 (1974) 172-194.

28. Stewart, T. (1997), Intellectual Capital: The New Wealth of Organizations,. New York, NY: Doubleday Dell Publishing Group. P. 368.

29. Stewart, T. (2003), The Wealth of Knowledge: Intellectual Capital and the Twenty-First Century Organization. NY: Doubleday Dell Publishing Group. P. 416

30. Stewart, T. (1991), Brainpower, Fortune, 3 June (1991) 42-60.

31. Strassmann, P.A. (2001), The value of knowledge capital, American Programmer, 11(3) (2001) 3-10.

32. Sveiby, K.E. (1997), The New Organizational Wealth: Managing and Measuring Knowledge Based Assets, Berrett Koehler, San Francisco, CA, URL: http://www.sveiby.com/articles/MeasureIntangibleAssets.html (дата обращения: 17.07.2010).

33. Van den Berg, Herman A. (2005), Models of Intellectual Capital Valuation: A Comparative Evaluation. Business Performance Measurement: Intellectual Capital - Valuation Models, Le Magnus University Press, (2005) 121-158.

34. Williams M. (2001), Is A Company's Intellectual Capital Performance And Intellectual 
Capital Disclosure Practices Related? Evidence From Publicly Listed Companies From The FTSE 100. McMasters Intellectual Capital Conference. Toronto.

Приложение 1

Модели оценки интеллектуального капитала

\begin{tabular}{|c|c|c|c|}
\hline \multirow[t]{2}{*}{ Качественные } & \multicolumn{2}{|c|}{ Количественные } & Другие \\
\hline & $\begin{array}{l}\text { Стоимость } \\
\text { затрат }\end{array}$ & $\begin{array}{l}\text { - Технологический Брокер (The } \\
\text { Technology Broker) }\end{array}$ & $\begin{array}{l}\text { Индекс уровня } \\
\text { знания } \\
\text { менеджмента }\end{array}$ \\
\hline $\begin{array}{l}\text { Теория } \quad \text { Конрад } \\
\text { групп }\end{array}$ & $\begin{array}{l}\text { Рыночная } \\
\text { оценка }\end{array}$ & $\begin{array}{l}\text { - Финансовый Метод Измерения } \\
\text { Неосязаемых Активов (Financial } \\
\text { Method of Intangible Assets } \\
\text { Measuring, FiMIAM) } \\
\text { - Соотношение Рыночной и } \\
\text { Балансовой стоимости (Market } \\
\text { over Book Value; Market to Book } \\
\text { Value) } \\
\text { - Q Тобина }\end{array}$ & $\begin{array}{l}\text { Реальные } \\
\text { опционы }\end{array}$ \\
\hline $\begin{array}{l}\text { Сбалансированная } \\
\text { система } \\
\text { показателей }\end{array}$ & $\begin{array}{ll}\text { Оценка на } \\
\text { основе } \\
\text { доходов }\end{array}$ & $\begin{array}{l}\text { - Экономическая Добавленная } \\
\text { стоимость (Есоnomic Value added, } \\
\text { EVA) } \\
\text { - Рассчитанная Стоимость } \\
\text { Неосязаемых Активов (Calculated } \\
\text { Intangible Value, CIV) } \\
\text { - Доходы от Капитала Знаний } \\
\text { (Кпоwledge Capital Earnings, КСЕ) } \\
\text { - Коэффициент Добавленной } \\
\text { Стоимости Интеллектуального } \\
\text { Капитала (Value Added Intellectual } \\
\text { Соеfficient, VAIC) }\end{array}$ & $\begin{array}{l}\text { В зависимости от } \\
\text { подтверждаемости }\end{array}$ \\
\hline Навигатор Скандиа & & & \\
\hline $\begin{array}{l}\text { Рейтинг } \\
\text { Интеллектуального } \\
\text { Капитала }\end{array}$ & & & \\
\hline $\begin{array}{l}\text { Индекс } \\
\text { Интеллектуального } \\
\text { Капитала }\end{array}$ & & & \\
\hline
\end{tabular}


Приложение 2

Достоинства и недостатки моделей оценки интеллектуального капитала

\begin{tabular}{|c|c|c|}
\hline Модель & Достоинства & Недостатки \\
\hline $\begin{array}{l}\text { Монитор } \\
\text { неосязаемых активов }\end{array}$ & $\begin{array}{l}\text { Понимание сильных и слабых } \\
\text { сторон } \\
\text { капитала компании }\end{array}$ & $\begin{array}{l}\text { Не имеет своим результатом совокупную } \\
\text { квантифицируемую стоимость }\end{array}$ \\
\hline $\begin{array}{l}\text { Система } \\
\text { Сбалансированных } \\
\text { показателей Нортона } \\
\text { Каплана }\end{array}$ & \begin{tabular}{lrr} 
Сильная & логика; & ясная \\
корреляция & \multicolumn{2}{c}{ между } \\
индикаторами & и & финансовыми \\
результатами & \multicolumn{2}{c}{ деятельности; } \\
хорошо & развитая \\
последовательная теория & и \\
\end{tabular} & \begin{tabular}{llr} 
Отсутствие & при & \multicolumn{2}{c}{ рассмотрении } \\
динамической & внешней & среды; \\
невозможность & проведения & внешнего \\
сравнительного & анализа; сложности в \\
квантификации & &
\end{tabular} \\
\hline Навигатор Скандиа & $\begin{array}{l}\text { Понимание сильных и слабых } \\
\text { сторон } \\
\text { капитала компании } \\
\end{array}$ & $\begin{array}{l}\text { Не имеет своим результатом совокупную } \\
\text { квантифицируемую стоимость }\end{array}$ \\
\hline $\begin{array}{l}\text { Технологический } \\
\text { брокер }\end{array}$ & $\begin{array}{l}\text { Позволяет провести аудит } \\
\text { компании на предмет наличия } \\
\text { интеллектуального капитала и } \\
\text { качества управления последним }\end{array}$ & $\begin{array}{lcr}\text { Сложности } & \text { в } & \text { квантификации; } \\
\text { сомнительная } & \text { степень } & \text { валидности } \\
\text { вопросов в ходе анкетирования }\end{array}$ \\
\hline $\begin{array}{l}\text { Соотношение } \\
\text { Рыночной } \\
\text { Балансовой } \\
\text { Стоимости }\end{array}$ & $\begin{array}{l}\text { Доступность информации при } \\
\text { расчете; легкость в понимании и } \\
\text { использовании }\end{array}$ & $\begin{array}{l}\text { Волатильность; неучет спекулятивной } \\
\text { составляющей на рынке капитала; } \\
\text { некорректность отражения балансовой } \\
\text { стоимости, основанной на исторических } \\
\text { затратах }\end{array}$ \\
\hline q Тобина & $\begin{array}{l}\text { Устранение эффекта различных } \\
\text { политик амортизации; легкость } \\
\text { в понимании и использовании } \\
\end{array}$ & $\begin{array}{l}\text { Труднодоступность информации п по } \\
\text { затратам на замещение }\end{array}$ \\
\hline $\begin{array}{l}\text { Экономическая } \\
\text { Добавленная } \\
\text { стоимость }\end{array}$ & 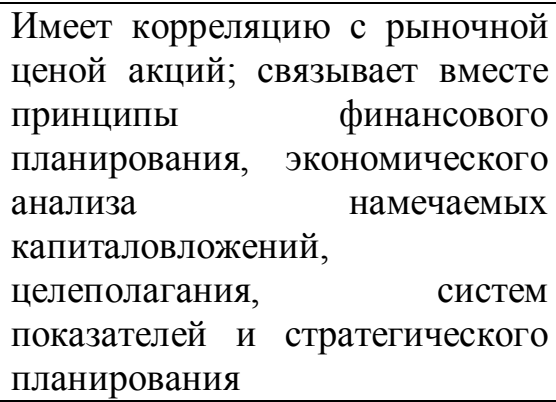 & $\begin{array}{l}\text { Сложная процедура корректировок; } \\
\text { подразумевает } \quad \text { управление компанией } \\
\text { только в интересах собственников }\end{array}$ \\
\hline $\begin{array}{l}\text { Рассчитанная } \\
\text { стоимость } \\
\text { неосязаемых активов }\end{array}$ & $\begin{array}{l}\text { Основывается на отраслевой } \\
\begin{array}{l}\text { информации; позволяет } \\
\text { понимать ценность бренда } \\
\text { компании }\end{array} \\
\end{array}$ & $\begin{array}{l}\text { Сложность в применении при отсутствие } \\
\text { аналогов в отрасли; неучет различных } \\
\text { политик амортизации }\end{array}$ \\
\hline Капитала & $\begin{array}{lr}\text { Производит оценку на основе } \\
\text { ожиданий; } & \text { обладает } \\
\text { прогностическими } \\
\text { характеристиками }\end{array}$ & $\begin{array}{lcr}\text { Требуется } & \text { усилия при } & \text { нормализации } \\
\text { доходов; } & \text { сложности } & \text { определения } \\
\text { доходности материальных и финансовых } \\
\text { активов }\end{array}$ \\
\hline $\begin{array}{l}\text { Коэффициент } \\
\text { Добавленной } \\
\text { Стоимости } \\
\text { Интеллектуального } \\
\text { Капитала }\end{array}$ & $\begin{array}{lr}\text { Предоставляет } & \text { некоторые } \\
\text { возможности } & \text { для } \\
\text { прогнозирования } & \text { и } \\
\text { внешнего/внутреннего } \\
\text { сравнения между } \\
\text { единицами }\end{array}$ & $\begin{array}{l}\text { Внутренние противоречия; сложно } \\
\text { квантифицировать данный показатель в } \\
\text { стоимостную оценку }\end{array}$ \\
\hline
\end{tabular}

